\title{
LA INTEGRACIÓN DE COMPETENCIAS EMOCIONALES EN EL CURRÍCULO DE LAS ENSEÑNANZAS REGLADAS DE DANZA DEL PAÍS VASCO
}

\section{Edurne Martínez Hervías}

Bailarina y coreógrafa

\section{Clara Urdangarin Liebaert}

Universidad del País Vasco / Euskal Herriko Unibertsitatea. Dpto Educación Física y Deportiva

\section{Resumen}

Las enseñanzas regladas de Danza construyen su metodología pedagógica sobre una educación emocional prácticamente inexistente. La integración de competencias emocionales en la enseñanza de esta disciplina artística y educativa es de vital importancia.

Analizamos el DECRETO 404/2013, de 30 de agosto, por el que se establece el currículo de las enseñanzas elementales de Danza, así como el DECRETO 252/2007, de 26 de diciembre, por el que se establece el currículo de las enseñanzas profesionales de Danza elaborados por el Gobierno Vasco.

Observamos que ambos hacen alusión al desarrollo de una serie de competencias emocionales. Sin embargo, no se realiza una propuesta específica sobre este aspecto generando un desequilibrio entre los efectos esperados y la realidad de la práctica educativa.

\section{Palabras clave: DANZA, ENSEÑANZAS ARTÍSTICAS, EDUCACIÓN, COMPETEN- CIAS EMOCIONALES}

\section{Abstract}

Dance formal education build their teaching methodology on an almost non-existent emotional education. The integration of emotional competencies in the teaching of this artistic and educational discipline is vital.

We analyze the DECREE 404/2013, of 30 August, establishing the curriculum of elementary Dance education, and the DECREE 252/2007 of 26 December, establishing the curriculum of professional Dance education developed by the Basque Government.

We note that both allude to the development of a series of emotional competencies. However, no specific proposal is made on this aspect creating an imbalance between expected effects and the reality of educational practice.

Keywords: DANCE; ARTS EDUCATION; EDUCATION; EMOTIONAL COMPETENCIES

\section{AUSART}




\section{INTRODUCCIÓN.}

En el ámbito profesional y no profesional de la danza existe el convencimiento de que esta disciplina artística contribuye al desarrollo motriz, cognitivo y socioemocional del individuo, en definitiva, al desarrollo integral de la persona (Laban 1984; Gardner 1998; Fuentes 2006). Sin embargo, la sola afirmación de que una actividad produce determinado efecto educativo no es suficiente para que así suceda (Parlebas 2012). Un estudio recientemente publicado advierte que "La danza en todas sus disciplinas comporta riesgos para la salud física, emocional y social de bailarines/as en los periodos de formación y de ejercicio profesional" (Pozo y Rodríguez 2014, 487). Tras esta afirmación cabe preguntarse qué es lo que sucede en la formación de profesionales de la danza para que el aprendizaje y la práctica de esta actividad pueda comportar riesgos no sólo físicos sino también emocionales y sociales. Las enseñanzas regladas de Danza construyen la identidad personal y profesional del alumnado mediante la interiorización de una serie de competencias que definen a una buena y a un buen intérprete. Creemos que estas competencias deben ir más allá de los conocimientos y las habilidades técnicas y expresivas propias de la danza y englobar también las competencias básicas para la vida, entre ellas las competencias emocionales. Una disciplina cuya finalidad es la expresión de emociones a través del dominio del cuerpo no debería comportar riesgos para la salud emocional de los profesionales y de los que se están formando en ella. Si la danza es emocionar y emocionarse, la integración de competencias emocionales en la enseñanza de esta disciplina artística y educativa es de vital importancia.

Las competencias pueden clasificarse en dos dimensiones: competencias de desarrollo técnico-profesional y competencias de desarrollo socio-personal (Bisquerra y Pérez Escoda 2007). Las primeras engloban competencias relacionadas con el conocimiento y procedimientos relativos a un ámbito profesional como: dominio de los conocimientos básicos y especializados, de las tareas, destrezas y técnicas necesarias en la profesión, capacidad de organización, coordinación, de adaptación e innovación, etc.

Las competencias socio-personales son aquellas de índole personal e interpersonal e integran las denominadas competencias básicas para la vida. Algunos ejemplos son: motivación, autoconfianza, autocontrol, paciencia, autocrítica, autonomía, control del estrés, asertividad, responsabilidad, capacidad de toma de decisiones, empatía, capacidad de resolución de conflictos y espíritu de equipo (Bisquerra y Pérez Escoda 2007). En este grupo se enmarcan las 
competencias emocionales: "conjunto de conocimientos, capacidades, habilidades y actitudes necesarias para comprender, expresar y regular de forma apropiada los fenómenos emocionales"(Bisquerra y Pérez Escoda 2007, 8). Según el modelo del GROP (Grup de Recerca en Orientació Psicopedagògica) de la Universidad de Barcelona hay cinco grandes competencias emocionales: conciencia emocional, regulación emocional, autonomía emocional, competencia social y habilidades de vida para el bienestar (Bisquerra, Pérez González y García Navarro 2015).

El fomento de este tipo de competencias es fundamental también en el periodo profesional de los y las intérpretes de danza ya que es un colectivo con riesgo de desarrollar disfunciones emocionales a lo largo de su carrera y estas competencias pueden ser un importante factor protector. Un estudio en relación al último periodo profesional y a los procesos de jubilación de este sector muestra que "el $70 \%$ de los bailarines estudiados refiere haber tenido problemas emocionales de diferente índole (problemas de autoestima, problemas alimentarios, dificultades con el alcohol, y algunas drogas, síntomas depresivos, trastornos del sueño, problemas de relación, problemas de pareja, fobia a volver al teatro, aislamiento, falta de sentido, crisis de identidad, ansiedad...)" (Cernuda 2014, 257).

\section{OBJETIVOS}

En este trabajo pretendemos observar de qué modo el currículo de las enseñanzas regladas de Danza del País Vasco integra las competencias de desarrollo socio-personal a la hora de plantear los objetivos, contenidos y criterios de evaluación. Y, si éstas se dirigen al desarrollo de competencias emocionales que el alumnado pueda necesitar tanto para el desempeño profesional de la danza como para el resto de ámbitos de su vida.

\section{METODOLOGÍA}

Analizamos el DECRETO 404/2013, de 30 de agosto, por el que se establece el currículo de las enseñanzas elementales de Danza y el acceso a dichas 
enseñanzas, así como el DECRETO 252/2007, de 26 de diciembre, por el que se establece el currículo de las enseñanzas profesionales de Danza y el acceso a dichas enseñanzas elaborados por el Departamento de Educación, Política Lingüística y Cultura, y el Departamento de Educación, Universidades e Investigación del Gobierno Vasco respectivamente. Estos Decretos son de aplicación en los conservatorios y centros de la Comunidad Autónoma de Euskadi autorizados para impartir dichas enseñanzas.

Las enseñanzas elementales de Danza se organizan en un grado de cuatro cursos de duración y las profesionales en un grado de seis cursos de duración. En la Comunidad Autónoma de Euskadi se oferta la especialidad de Danza Clásica. Las asignaturas de Danza Académica (en las enseñanzas elementales) y Danza Clásica (en las profesionales) tienen una carga lectiva muy superior al resto y forman parte del entrenamiento diario del alumnado. Por ese motivo, hemos centrado el estudio en el currículo de las asignaturas de Danza Académica y Danza Clásica.

\section{RESULTADOS}

Al analizar los objetivos, contenidos y criterios de evaluación de la asignatura de Danza Académica de las enseñanzas elementales y de la asignatura de Danza Clásica en las profesionales, observamos que todos los planteamientos hacen referencia al desarrollo de competencias de nivel técnico y expresivo del movimiento. A habilidades físicas que familiarizan al alumnado con el vocabulario de la Danza Clásica y con los hábitos específicos de trabajo en el aula. Quedan sin definir contenidos que permitan el desarrollo de habilidades personales, sociales y emocionales.

De hecho, para encontrar alguna referencia al desarrollo de estas habilidades, hay que remitirse a las explicaciones que introducen de modo global las finalidades y objetivos de estas enseñanzas. De ese apartado general hemos podido extraer aquellas competencias socio-personales características de las enseñanzas regladas de Danza.

En la siguiente tabla presentamos aquellos objetivos que incluyen alguna referencia al desarrollo personal, social o emocional del alumnado. En la tabla se 
incluyen también aquellas competencias socio-personales que creemos pueden estar definidas dentro de estos objetivos.

Tabla : Objetivos y competencias de desarrollo personal, social o emocional de las enseñanzas regladas de Danza'.

\begin{tabular}{|c|c|}
\hline OBJETIVOS & COMPETENCIAS \\
\hline $\begin{array}{l}\text { - Aprender a dirigir los esfuerzos hacia metas con- } \\
\text { cretas. }\end{array}$ & Motivación \\
\hline Mostrar una actitud de superación constante. & Autoexigencia \\
\hline $\begin{array}{l}\text { - Formarse una imagen ajustada de sí mismo, de } \\
\text { sus características y posibilidades, y desarrollar }\end{array}$ & Constancia \\
\hline $\begin{array}{l}\text { hábitos del estudio, valorando el rendimiento en } \\
\text { relación con el tiempo empleado. }\end{array}$ & Autocrítica \\
\hline $\begin{array}{l}\text { - Tener la disposición necesaria para saber inte- } \\
\text { grarse en un grupo como un miembro más del }\end{array}$ & Espíritu de equipo \\
\hline $\begin{array}{l}\text { mismo o para actuar como responsable del con- } \\
\text { junto. }\end{array}$ & $\begin{array}{l}\text { Capacidad de } \\
\text { resolución de }\end{array}$ \\
\hline - Reaccionar con los reflejos necesarios que & \\
\hline $\begin{array}{l}\text { requiere la solución de los problemas que puedan } \\
\text { surgir durante la interpretación. }\end{array}$ & $\begin{array}{l}\text { Sensibilidad } \\
\text { estética }\end{array}$ \\
\hline $\begin{array}{l}\text { Desarrollar la sensibilidad artística y el criterio } \\
\text { estético como fuente de formación y enriqueci- } \\
\text { miento personal. }\end{array}$ & $\begin{array}{l}\text { Conocimiento del } \\
\text { propio cuerpo }\end{array}$ \\
\hline $\begin{array}{l}\text { Profundizar en el conocimiento corporal y emocio- } \\
\text { nal para mantener el adecuado equilibrio y bienes- } \\
\text { tar psicofísico. }\end{array}$ & $\begin{array}{l}\text { Conocimiento de } \\
\text { las propias emo- } \\
\text { ciones }\end{array}$ \\
\hline
\end{tabular}

Observamos que la mayoría de estos objetivos hacen referencia a las habilidades específicas para la danza, y no se dirigen al desarrollo de competencias básicas que pueda necesitar el alumnado en el resto de ámbitos de su vida. Creemos que éstas competencias pertenecerían más bien a la dimensión de competencias técnico-profesionales que tienen que ver con el "hacer" y el "saber hacer" propios de la especialidad. Ponen en valor los rasgos y valores que según la cultura profesional dominante de este sector definen a un buen y una buena artista.

En relación al desarrollo de competencias emocionales, encontramos un único objetivo: "profundizar en el conocimiento corporal y emocional para mantener 
el adecuado equilibrio y bienestar psicofísico." Que el alumnado sea capaz de conocer y expresar sus propias emociones es primordial a la hora de crear una conciencia de cuidado de la salud emocional y física en el sector de la danza: "En este mundo, el cuidado de la salud de los bailarines no tiene sentido, pasa a segundo término ante las exigencias de la formación, de la profesión y de la obra" (Pozo y Rodríguez del Barrio 2014, 489).

\section{CONCLUSIONES}

El currículo de las enseñanzas regladas de Danza del País Vasco integra competencias dirigidas al desarrollo de conocimientos técnicos y expresivos y a la adquisición de una serie de hábitos identitarios de la cultura profesional del sector de la danza. Aunque uno de los objetivos generales de estas enseñanzas hace referencia al bienestar psicofísico del alumnado, el currículo de las asignaturas no integra contenidos dirigidos al desarrollo de competencias emocionales que el alumnado pueda necesitar en el resto de ámbitos de su vida. El planteamiento definido en el currículo de estas enseñanzas no es suficiente para contribuir al desarrollo integral de la persona.

El entrenamiento diario de estas enseñanzas es la clase de técnica de danza clásica estructurada en ejercicios de barra y de centro. Los rasgos de lógica interna de esta situación motriz nos permiten clasificarla dentro de las prácticas motrices que se realizan en solitario (psicomotoras) y en un medio estable. En la clase de danza clásica se automatizan estereotipos motores y se explora y se conoce el propio cuerpo desde dentro. Se trata de una situación que puede generar conductas motrices asociadas a la constancia, el auto-esfuerzo, el sacrificio, el conocimiento de uno mismo (Lavega 2011). En este sentido, no debemos olvidar que la danza clásica tiene su origen en un periodo en el que "el cuerpo danzante fue reducido a un conjunto de normas, a una abstracción o a un modelo canónico adaptado a factores estéticos derivados del juicio moral y de las razones ideológicas propias de su contexto" (Nordera 2011, 117).

Si cada situación motriz genera una experiencia concreta en el actuante producto de su lógica interna, en las enseñanzas regladas de Danza es necesario fomentar situaciones en las que el alumnado pueda desarrollar y adquirir capacidades socio-personales que le ayuden a desarrollar una experiencia 
positiva a lo largo de su carrera y de su vida. La integración de competencias emocionales en el currículo de las enseñanzas regladas de Danza nos permitiría atender la dimensión afectiva de los sujetos. De este modo podríamos hablar de la formación en danza como un medio para favorecer el desarrollo socioemocional de las personas. Su experiencia artística se vería, sin duda, reforzada. Como ha apuntado, Martha Myers, Decana Emérita del American Dance Festival, en las enseñanzas de danza debería educarse para la vida y no sólo para la danza: "We train students for life, not just dance. Dance is about life, creativity, people, and being flexible, open to change, and having experience in decision-making. Training should encompass coping with these elements" (Wang et al. 1995, 83).

\section{RECONOCIMIENTOS}

Manifestamos el reconocimiento al apoyo del Ministerio de Economía y Competitividad, Secretaría de Estado de Investigación Desarrollo e Innovación a través del programa I+D+i del Gobierno Español al proyecto "La perspectiva de género en las emociones suscitadas en los juegos deportivos" (código DEP2010-21626-C03-02).

\section{Referencias}

Bisquerra Alzina, Rafael. 2000. Educación emocional y bienestar. Barcelona: Praxis

Bisquerra Alzina, Rafael y Nuria Pérez Escoda. 2007. “Las competencias emocionales”. Educación XXI 10: 61-82

Bisquerra Alzina, Rafael, Juan Carlos Pérez González y Esther García Navarro. 2015. Inteligencia emocional y en educación. Madrid: Síntesis

Cernuda, Amador. 2014. "Efectos psicológicos y sociales del proceso de jubilación del bailarín profesional”. Pp. 253-58 en La investigación en Danza en España 2014, III Congreso Nacional "La Investigación en Danza" (Bilbao). Valencia: Mahali

Fuentes Serrano, Ángel Luis. 2006. El valor pedagógico de la danza. Tesis doctoral. Valencia: Universidad de Valencia

Gardner, Howard. 1998. Inteligencias múltiples: La teoría en la práctica. Barcelona: Paidós

Hanna, Judith Lynne. 1999. Partnering dance and education: intelligent moves for changing times. Champaign, Illinois: Human Kinetics

Laban, Rudolf. 1984. Danza educativa moderna. Barcelona: Paidós 
Lavega Burgués, Pere. 2011. "Dominios de acción motriz y afectividad". XIV Seminario Internacional y II Latinoamericano de Praxiología Motriz (12-15 oct.). La Plata: Universidad Nacional de La Plata. www.memoria.fahce.unlp.edu.ar/trab eventos/ev.1413/ev.1413.pdf

Nordera, Marina. 2011. "Ser bailarina en el siglo XVIII: El cuerpo femenino entre la sociedad y la escena". Pp. 117-138 en Coreografiar la historia europea: Cuerpo, política, identidad y género en la danza, editado por Beatriz Martínez del Fresno. Oviedo: Universidad de Oviedo

Parlebas, Pierre 2012. Juegos, deporte y sociedad: Léxico de praxiología motriz. Barcelona: Paidotribo

Pozo Municio, María Concepción y Aurora Rodríguez del Barrio. 2014. "La relación del profesional de la danza con el pavimento: El lugar del cuidado y la prevención de riesgos entre los bailarines y bailarinas". Pp. 485-94 en La investigación en Danza en España 2014, III Congreso Nacional "La Investigación en Danza" (Bilbao). Valencia: Mahali

Thomas, Helen. 2003. The Body, Dance and Cultural Theory. London: Macmillan

Urdangarin Liebaert, Clara. 2009. "Bailando jauzi bajo barras y estrellas: Una etnografía del Zazpiak Bat Group of Dancers de Reno, Nevada". Tesis doctoral, Universidad del País Vasco /Euskal Herriko Unibertsitatea

Wang, Lan-Lan, Viola Farber, Susan Sgorbati, Peggy Schwartz \& Martha Myers. 1995. "Dancers in cap and gown: Northeast College Dance Festival". Dance Magazine (December): $82-4$

\section{Normas jurídicas}

Decreto 252/2007, de 26 de diciembre, por el que se establece el currículo de las enseñanzas profesionales de Danza y el acceso a dichas enseñanzas (BOPV núm. 53 de14 de marzo de 2008)

Decreto 404/2013, de 30 de agosto, por el que se establece el currículo de las enseñanzas elementales de Danza y el acceso a dichas enseñanzas (BOPV núm. 195 de 11 de octubre de 2013)

(Endnotes)

Notas

1 Según lo estipulado en el Decreto 404/2013, de 30 de agosto, por el que se establece el currículo de las enseñanzas elementales de Danza, y en el Decreto 252/2007, de 26 de diciembre, por el que se establece el currículo de las enseñanzas profesionales de Danza, elaborados por el Gobierno Vasco 